\title{
$A B C B 1$ and $A B C G 2$ drug transporters are differentially expressed in non-small cell lung cancers (NSCLC) and expression is modified by cisplatin treatment via altered Wnt signaling
}

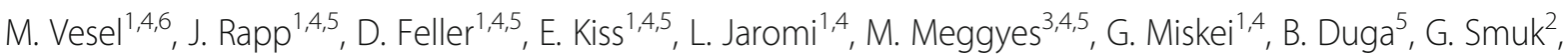
T. Laszlo ${ }^{2}$, I. Karner ${ }^{7}$ and J.E. Pongracz ${ }^{1,4,5^{*}}$

\begin{abstract}
Background: Lung cancer (LC) is still the most common cause of cancer related deaths worldwide. Non-small cell lung cancer (NSCLC) accounts for $85 \%$ of all LC cases but is not a single entity. It is now accepted that, apart from the characteristic driver mutations, the unique molecular signatures of adeno- (AC) and squamous cell carcinomas (SCC), the two most common NSCLC subtypes should be taken into consideration for their management. Therapeutic interventions, however, frequently lead to chemotherapy resistance highlighting the need for in-depth analysis of regulatory mechanisms of multidrug resistance to increase therapeutic efficiency.

Methods: Non-canonical Wnt5a and canonical Wnt7b and ABC transporter expressions were tested in primary human LC $(n=90)$ resections of AC and SCC. To investigate drug transporter activity, a three dimensional (3D) human lung aggregate tissue model was set up using differentiated primary human lung cell types. Following modification of the canonical, beta-catenin dependent Wnt pathway or treatment with cisplatin, drug transporter analysis was performed at mRNA, protein and functional level using qRT-PCR, immunohistochemistry, immune-fluorescent staining and transport function analysis.

Results: Non-canonical Wnt5a is significantly up-regulated in SCC samples making the microenvironment different from $A C$, where the beta-catenin dependent Wnt7b is more prominent. In primary cancer tissues $A B C B 1$ and $A B C G 2$ expression levels were different in the two NSCLC subtypes. Non-canonical rhWnt5a induced down-regulation of both $A B C B 1$ and $A B C G 2$ transporters in the primary human lung aggregate tissue model recreating the SCC-like transporter pattern. Inhibition of the beta-catenin or canonical Wnt pathway resulted in similar down-regulation of both ABC transporter expression and function. In contrast, cisplatin, the frequently used adjuvant chemotherapeutic agent, activated beta-catenin dependent signaling that lead to up-regulation of both ABCB1 and ABCG2 transporter expression and activity.

(Continued on next page)
\end{abstract}

\footnotetext{
* Correspondence: pongracz.e.judit@pte.hu

'Department of Pharmaceutical Biotechnology, School of Pharmacy,

University of Pecs, Pecs, Hungary

${ }^{4}$ Szentagothai Research Centre, University of Pecs, Pecs, Hungary

Full list of author information is available at the end of the article
} 
(Continued from previous page)

Conclusions: The difference in the Wnt microenvironment in AC and SCC leads to variations in ABC transporter expression. Cisplatin via induction of canonical Wnt signaling up-regulates ABCB1 and ABCG2 drug transporters that are not transporters for cisplatin itself but are transporters for drugs that are frequently used in combination therapy with cisplatin modulating drug response.

Keywords: $A B C$ transporters, Wnt signaling, Cisplatin, Lung cancer

\section{Background}

Despite of the alarming statistics of lung cancer incidence and mortality rates, development of an allaround successful therapy remains elusive. Partly, as lung cancers (LC) are highly diverse and apart from small (SCLC) and non-small cell lung cancers (NSCLC) there are morphologically diverse subtypes that are frequently mixed. Additionally, their clinical characteristics and drug sensitivity also varies greatly. As there are no available targeted therapies for each variation, the treatment approaches are similar and the overall prognoses are still grim.

The 5 year survival rate of NSCLC varies from $73 \%$ in early detection (stage IA) to $3.7 \%$ at advanced metastatic disease [1, 2]. At early stages of NSCLC surgery and chemotherapy are still the choices of first line treatment $[3,4]$, although targeted molecular therapies are now more widely included in the treatment regimen. Targeted therapies that can extend progression free and overall survival are only available to a fraction of patients as such approaches require the presence of mutations or amplifications of specific genes most frequently KRAS, EGFR or ALK $[1,5,6]$.

Unfortunately, the majority of patients are presented at advanced or even metastatic stage of the disease

Table 1 List of gene specific primers used in qRT-PCR

\begin{tabular}{lll}
\hline Target & Accession number & sequence \\
\hline $\begin{array}{l}\text { human beta-actin } \\
\text { (ACTB) }\end{array}$ & NM_001101 & for-GCGCGGCTACAGCTTCA \\
human ABCB1 & NM_000927 & $\begin{array}{l}\text { for-GCAGCTGATGTCACGCACGATTCCACAAATACACAA } \\
\text { rev-CCCAACATCGTGCACATCA }\end{array}$ \\
human ABCG2 & NM_004827 & for-AACCTGGTCTCAACGCCATC \\
& & rev-GTCGCGGTGCTCCATTATC \\
human ABCC1 & NM_004996.3 & for-GCTGGAGTGTGTGGGCAACT \\
& & rev-CTGAGGCTGTGCCTGGAGAT \\
human ABCC2 & NM_000392 & for-GCAAACTGTTCTGGTGTGGA \\
& & rev-CCAGCTCTATGGCTGCTAGA \\
human Wnt5a & NM_003392 & for-CCTGCTCCTGACCGTCC \\
& & rev-CAAAGCAACTCCTGGGCTTA \\
human Wnt7b & NM_058238 & for-GTCCTGTACGTGAAGCTCGG \\
& & rev-CGGAACTGGTACTGGCACTC \\
\hline
\end{tabular}

where surgical resection is not an option. Cisplatin based therapy can increase the survival rates in all stages but chemotherapy resistance and disease recurrence remain major issues. In metastatic disease, treatment is frequently based on the combination therapies of cisplatin or carboplatin with drugs such as paclitaxel, docetaxel, gemcitabine and vinorelbine to increase efficacy compared to single agent platinum therapy [7]. And although the use of immune modulators (e.g. Nivolumab) has become a promising route to effectively halt disease progression, their application in fast progressing tumor types require further analysis including drug interaction studies between small molecules and biological therapies [8].

Studies of influx and efflux mechanisms of drug transporters might help to evaluate effectiveness of drugs in therapy. In various studies ATP-binding cassette (ABC) transporter family members, such as ABCB1 (MDR1 or Pgp) and ABCG2 (BCRP1) are involved in drug resistance $[9,10]$. While cisplatin is not an ABCB1 or ABCG2 substrate $[11,12]$, association studies implicated ABCG2 as a predictive factor for poor clinical outcome of advanced NSCLCs [13]. The link of ABCB1 to NSCLC chemoresistance remained inconclusive [14-16], although drugs like erlotinib, irinotecan etc. that are widely used in combination therapy of NSCLC are ABCB1 and ABCG2 substrates $[17,18]$.

Interestingly, it has recently been shown that TCF/LEF dependent signaling activates the ABCB1 promoter indicating that beta-catenin dependent Wnt signaling [19] is involved in ABCB1 expression [20] and therefore potentially in chemoresistance [21, 22]. The highly complex and evolutionarily conserved Wnt signaling pathway controls many developmental and tissue maintenance events via the canonical or beta-catenin dependent, and two non-canonical pathways [19]. Previous studies have shown that Wnt pathway, although rarely mutated, is differentially regulated in LC subtypes. While beta-catenin dependent signaling can be strongly down-regulated in SCLC through over-expression of inhibitory genes differential activation of the beta-catenin dependent canonical and $\mathrm{Ca}^{2+}$ dependent non-canonical Wnt pathways have been reported in NSCLC subtypes of AC and SCC, respectively [23, 24].

As resistance to chemotherapy is a major obstacle to successful treatment of lung cancer and resistance is 
strongly associated with influx and efflux drug transporters, we have theorized that the generally applied platinum-based therapy might be able to affect drug transporter expression and activity via modulation of Wnt signaling. Thus, the aim of the present study was to test the following hypotheses: (i) Expression of $\mathrm{ABC}$ transporters are different in $\mathrm{AC}$ and $\mathrm{SCC}$ subtypes of NSCLC patients due to the highly diverse Wnt microenvironment; and (ii) Differential expression and functionality of $\mathrm{ABCB} 1$ and $\mathrm{ABCG} 2$ are directly regulated by cisplatin modified Wnt signaling leading to altered response to second in line drugs.

\section{Methods}

\section{Ethical Statement}

Lung tissue samples were collected at the Department of Surgery coordinated by the Department of Pathology, University of Pecs, Hungary. The project was approved by the Ethical Committee of the University of Pecs (ETT-TUKEB 366/2015). Patients had given written consent to provide samples for research purposes. All collected samples were treated anonymously.

\section{Human lung samples}

A total of 90 patient samples were processed, 76 adenocarcinomas and 14 squamous cell carcinomas that were collected at the Department of Surgery, assessed by a certified lung pathologist based on WHO guidelines.

\section{Cell culture}

Primary human small airway epithelial cells (SAEC), normal human lung fibroblasts cells (NHLF) and normal human lung microvascular endothelial cells (HMVEC-L) were cultured according to the manufacturers' recommendations (Lonza, Basel, Switzerland). Briefly, cells were thawed and cultured as monolayer in Small Airway Growth Medium (SAGM), Fibroblast Growth Medium (FGM-2) and Endothelial Growth Medium (EGM-2) respectively at $37{ }^{\circ} \mathrm{C}$ in humidified atmosphere containing $5 \% \mathrm{CO}_{2}$. A549 lung adenocarcinoma were grown in complete DMEM containing 10\% FBS and H520 lung squamous carcinoma cells (American Type Culture Collection, Rockville, MD) were cultured in complete RPMI containing $10 \% \mathrm{FBS}$ at $37{ }^{\circ} \mathrm{C}$ in humidified atmosphere containing $5 \% \mathrm{CO}_{2}$. Trypan blue dye exclusion test was used to assess cell viability in all culture types.

\section{Drugs used in the experiments}

Cisplatin, Paclitaxel, Doxorubicin and Gemcitabine were all purchased from Selleck Chemicals (Selleck Chemicals, Houston, USA). Treatments were conducted at final concentrations as follows cisplatin of $29.7 \mu \mathrm{M}$ [25], paclitaxel of $100 \mathrm{nM}$ [26], doxorubicin of $100 \mathrm{nM}$ [26] and gemcitabine of $100 \mathrm{nM}$ [26].

\section{Cellular fractionation and Western-blot analysis}

A549 lung adenocarcinoma cells (American Type Culture Collection, Rockville, MD) were grown in complete DMEM until reaching 70\% confluence. Cells were treated for $3 \mathrm{~h}$ with cisplatin (Selleck Chemicals, Houston, USA) at final concentration of $29.7 \mu \mathrm{M}$ [25]. All experiments were done in triplicates. After treatment, cells were rinsed with PBS and collected with trypsin, then proceeded with protocol for cell compartment isolation. A549 cells were used between passage number 8 to 10 and epithelial characteristics were proved by cytokeratin positivity. All the cell cultures were regularly tested for mycoplasma infection [27].

\section{D lung aggregate cultures}

Aggregates containing NHLF, SAEC and HMVEC-L cells were mixed at 4:3:3 ratio, and dispensed onto polyHEMA-coated (final concentration $20 \mathrm{mg} / \mathrm{ml}$ ) 96-well plates (TPP, Sigma-Aldrich, St. Louis, USA) as described earlier [28]. The plates were centrifuged for $10 \mathrm{~min}$ at $600 \mathrm{x} \mathrm{g}$ at $4{ }^{\circ} \mathrm{C}$. The final number of cells/well was 30.000. Aggregates were grown in SAGM/EGM-2/FGM2 media at 2:2:1 ratio. After $24 \mathrm{~h} 3 \mathrm{D}$ aggregates were transferred on a 24 well plate (also coated with polyHEMA) and treated with recombinant human Wnt5a at final concentration of $1 \mu \mathrm{g} / \mathrm{ml}$ for $72 \mathrm{~h}$ (Chinese Hamster Ovary Cell Line, CHO-derived Gln38-Lys380) (R\&D Systems, Minneapolis, USA) [23], cisplatin (Selleck Chemicals, Houston, USA) (29.7 $\mu \mathrm{M}$ for $72 \mathrm{~h}$ ) [25], IWR-1 (Sigma Aldrich, St. Louis, USA) $(1 \mu \mathrm{M}$ for $3 \mathrm{~h}$ ) [23] and $\mathrm{LiCl}$ (Sigma Aldrich, St. Louis, USA) $(10 \mathrm{mM}$ for $3 \mathrm{~h})$ [29]. Upon treatment they were collected in RA1 Buffer Solution for RNA isolation, into cryostat embedding medium for dissection or used for drug transporter functional test.

\section{RNA isolation, CDNA synthesis and qRT-PCR}

3D aggregates were collected in RA1 Buffer Solution then on-column RNA isolation was performed according to the manufacturers' protocol (NucleoSpinII RNA isolation kit, Macherey-Nagel, Düren, Germany). Total RNA from frozen human lung samples was isolated using TRI Reagent (Invitrogen, Thermo Fisher Scientific, Waltham, USA) with an additional DNase (Sigma-Aldrich, St Louis, USA) treatment. RNA concentration was measured using Nanodrop technology (Thermo Fisher Scientific, Waltham, USA).

cDNA synthesis was performed using random hexamer primers of the high capacity RNA to cDNA kit (Thermo Fisher Scientific, Waltham, USA) according to the manufacturers' protocol.

SYBRGreen (Bioline, London, UK) real-time qRT-PCR reaction (Table 1) was set up using StepOne and StepOne Plus instruments (Thermo Fisher Scientific, Waltham, 
USA). For human samples, only samples with beta-actin $\mathrm{Ct}$ values below 22.5 were used for further evaluation. The relative quantities of different drug-transporters were calculated using the $2^{\text {-ddCt }}$ method. The reference gene was beta-actin for all the samples.

\section{Fluorescent staining and immunohistochemistry}

Sections of 3D aggregate co-cultures were sectioned frozen and fixed with either acetone or 4\% PFA (paraformaldehyde) solution (depending on the primary antibody used), and then stained by standard staining procedure. Briefly, blocking was done with 5\% BSA/PBS solution; primary antibodies were diluted in the blocking solution and incubated for $1 \mathrm{~h}$ at room temperature. After washing the slides in PBS three times for $5 \mathrm{~min}$, secondary antibody was applied for $45 \mathrm{~min}$. Slides were then washed and the nuclei were stained using TO-PRO-3 (Thermo Fisher Scientific, Waltham, USA) in 1:1000 dilutions for $15 \mathrm{~min}$. Slides were washed again and covered with Vectashield (Vector Laboratories, Burlingame, CA, USA) solution. Primary antibodies of mouse monoclonal anti human beta-catenin (E-5 clone, sc-7963, SantaCruz Biotechnology, Dallas, TX, USA) were diluted 1:50, while the rabbit monoclonal anti human phospho-beta-catenin (Ser675) (4176S, Cell Signaling Technology, Danvers, USA) antibody was used in 1:100 dilutions. Secondary antibodies were AlexaFluor-488 conjugated anti-rabbit and anti-mouse IgG antibodies from Thermo Fisher Scientific (Waltham, USA) diluted 1:200. The pictures were taken with Zeiss LSM 710 confocal microscope (Zeiss, Oberkochen, Germany), always first adjusting the parameters to the secondary antibody control and then inspecting the actual slides using the same settings. Images were evaluated using Fiji [30].

\section{Immunohystochemical staining of $A B C$ transporters and Wnt ligands}

Primary lung tissue and 3D co-cultures sections were cut using Leica CM1950 cryostat (Leica, Wetzlar, Germany) then fixed and stained with a routine IHC staining procedure using Vision Biosystems bond ${ }^{\mathrm{m}}$ automated immunostainer (Leica, Wetzlar, Germany). Primary antibody of mouse monoclonal anti-human ABCG2 (CD338, clone 5D3, BD Biosciences, San Jose, USA) was used in 1:50 dilution and rabbit monoclonal anti-human ABCB1 (1:50, clone D3H1Q, Cell Signaling Technology, Danvers, USA). Rat monoclonal anti-human Wnt5a (clone 442625) and goat polyclonal anti-human Wnt7b antibodies were purchased from R\&D Systems, (Minneapolis, USA) and used in 1:50 dilutions.

\section{Functionality test of drug transporters}

All experiments were done using the "eFluxx-ID" Green multidrug resistance assay kit" (ENZO, Enzo Life Sciences,
Farmingdale, New York, USA) according to the manufacturers' protocol. Briefly, 3D aggregates were enzymatically digested using Accumax solution (Sigma Aldrich, St. Louis, USA) and single cell suspension were mixed with diluted drug transporter inhibitor molecules, incubated for $5 \mathrm{~min}$ at $37^{\circ} \mathrm{C}$, then all samples were incubated with diluted eFluxx-ID ${ }^{\circ}$ Green dye for $30 \mathrm{~min}$ at $37^{\circ} \mathrm{C}$. After $30 \mathrm{~min}$, propidium-iodide was added to all sample tubes and were measured immediately with FACS Canto II flow cytometer (BD, Biosciences, Immunocytometry Systems, Erembodegen, Belgium). Appropriated controls (stained and unstained) were included into procedure. The results are calculated as multidrug resistance (MDR) activity factor values (MAF).

\section{Cell compartment fractionation and Western-blotting}

Cell compartment factions were obtained using Qproteome ${ }^{\circledR}$ Cell Compartment Kit (Qiagen, Hileden, Germany) according to the manufacturer's recommendation. Cell compartment protein fractions were acetone precipitated. Protein content was then measured using Protein Assay Kit measured with Qubit $^{\circ}$ fluorometer (Thermo Fisher Scientific, Waltham, USA). Samples were mixed with $4 \times$ Laemmli sample buffer (BIO-RAD Laboratories, Hercules, California, USA) and heated to $90{ }^{\circ} \mathrm{C}$ for $5 \mathrm{~min}$. SDSelectrophoresis was performed using Mini-Protean TGX Precast Gels (BIO-RAD Laboratories, Hercules, California, USA), at $125 \mathrm{~mA}$ current. Blotting was done for $3 \mathrm{~h}$ at $140 \mathrm{~V}$ with nitrocellulose membrane (GE Healthcare Life Sciences, Little Chalfont, UK). The membranes were blocked for $1 \mathrm{~h}$ using $5 \%$ milk powder in PBS solution. The primary antibody was rabbit anti-human beta-catenin (clone D10A8, Cell Signaling Technology, Danvers, USA), rabbit anti-human phospho-beta-catenin (clone D2F1, Cell Signaling Technology, Danvers, USA) in 1:1000 dilution and mouse anti-human beta-actin (clone AC-74, SigmaAldrich, St. Louis, USA) in 1:2000 overnight. Secondary antibody was goat anti-rabbit and anti-mouse IgG-HRP conjugate (BIO-RAD Laboratories, Hercules, California, USA) in 1:1000 dilution for $1 \mathrm{~h}$. The proteins were detected using SuperSignal West Femto Maximum Sensitivity Substrate (Thermo Fisher Scientific, Waltham, USA) and documented with ImageQuant LAS4000 CCD camera system (Fujifilm, GE Healthcare Life Science, Little Chalfont, UK). Pictures were processed using Fiji [30].

\section{Statistical analysis}

Kolmogorov-Smirnov test was used to determine the distribution of variables. Nonparametric tests were applied for the variables with no Gaussian distribution. KruskalWallis test was used for effective differences among all groups. For comparing differences between groups in continuous variables with non-normal distribution MannWhitney-U tests were appropriate. Spearman correlation 
test was adequate to rank and measure the relationship between two continuous random variables. SPSS 22.0 package for Windows (SPSS Inc., Chicago, IL, USA) was applied for all statistical analyses. Differences were considered statistically significant at ${ }^{*} P<0.05,{ }^{* *} P<0.01$ and $\because * P<0.001$.

\section{Results}

\section{$A B C B 1$ and $A B C G 2$ transporters are differentially} expressed in primary $A C$ and $S C C$

mRNA levels of ABCB1 and ABCG2 transporters were investigated in 90 resected, primary human lung $A C$ and SCC tissue samples by qRT-PCR and immunohistochemistry (Fig. 1a, c). Data revealed significant differences in both ABCB1 and ABCG2 mRNA expression levels messages being higher in AC compared to SCC (Fig. 1a). Reflecting mRNA, ABCB1 protein was strongly expressed in AC but not in SCC (Fig. 1c) while ABCG2 levels were barely detectable in $\mathrm{AC}$ and non-detectable in SCC samples (Additional file 1: Figure S1). As the Wnt molecular background of AC and SCC differ (Fig. 1b, d), understanding any connections between the underlying molecular differences in the Wnt pathways and drug transporter induced chemoresistance can only become possible if in vitro studies are available. To model the microenvironment of the pulmonary tissue, 3D aggregate cultures were set up using primary human lung cell types HMVEC-L, SAEC and NHLF derived from commercially available healthy human donor tissues. Analysis of the aggregates revealed that ABCB1 and ABCG2 drug transporters at message levels were similar to that of primary healthy human lungs, and both transporters were expressed as active proteins (Additional file 2: Figure S2) making the model suitable for drug transporter regulation studies.

\section{Wnt dependent differential regulation of drug transporter expression}

As differences were detected in beta-catenin dependent canonical (Wnt7b) and $\mathrm{Ca}^{2+}$ dependent non-canonical Wnt5a expression in AC and SCC [23] (Fig. 1b, d), respectively, the AC-like canonical Wnt pathway activation was mimicked in the lung tissue aggregate by stimulating the canonical Wnt signaling pathway using
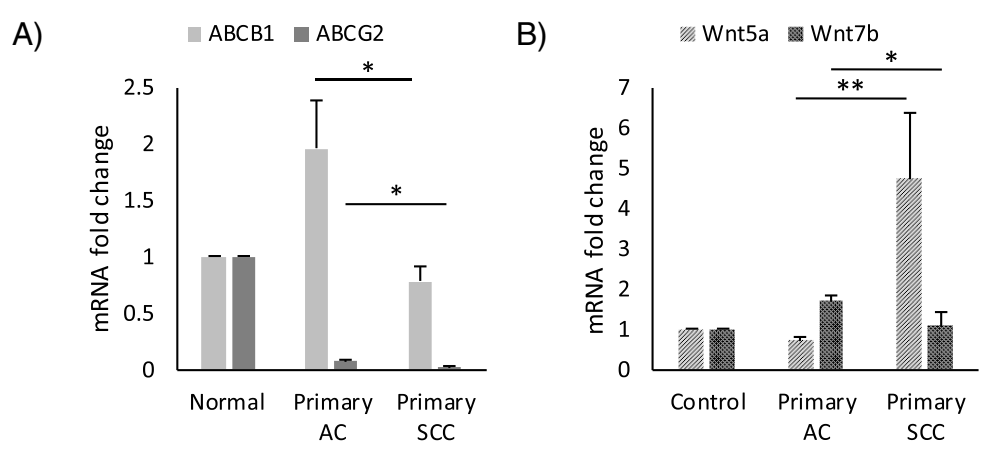

C)
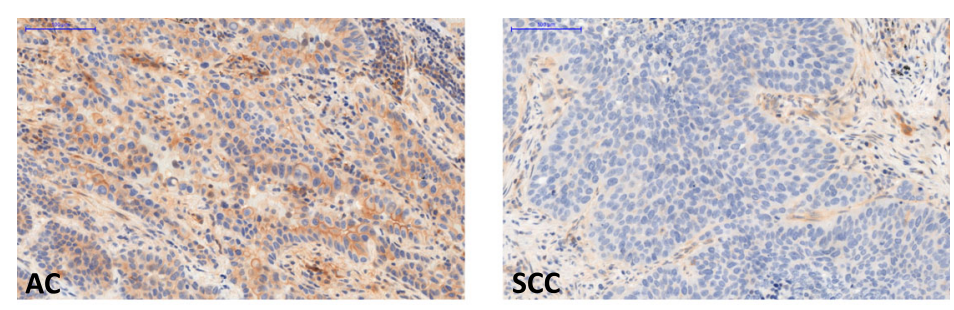

D)
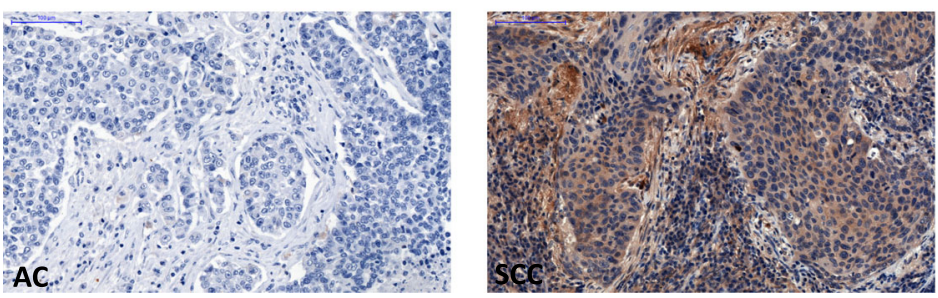

Fig. 1 Drug transporter and Wnt microenvironment analysis of primary human AC and SCC samples. Relative mRNA expression of a) ABCB1 and ABCG2 drug transporters and $\mathbf{b}$ ) non-canonical Wnt5a and canonical Wnt7b in primary human AC and SCC samples. mRNA expression is relative to normal, healthy lung tissue. $n=76$ for AC, and $n=14$ for SCC. Data are presented as mean \pm SEM. Immunohistochemistry of primary AC and SCC of c) ABCB1 drug transporter protein staining ( $n=5$ each) and $\mathbf{d}$ ) Wnt5a ligand protein staining ( $n=5$ each). Magnification is $20 \times$, scale bar $100 \mu \mathrm{m}$ 
$\mathrm{LiCl}$ (at $10 \mathrm{mM}$ final concentration) [31], the chemical activator of the beta-catenin pathway. As non-canonical pathway signals suppress the beta-catenin driven gene transcription, the SCC dependent Wnt microenvironment was simulated by the beta-catenin pathway inhibitor IWR $(1 \mu \mathrm{M})[23]$ as well as treating the cultures with rhWnt5a $(1 \mu \mathrm{g} / \mathrm{ml}$ final concentration).

Chemical modification of Wnt signaling revealed that inhibition of beta-catenin down-regulates both ABCB1 and ABCG2 (Fig. 2a), while activation of beta-catenin significantly up-regulates the expression of both transporters (Fig. 2a). Treatment of lung aggregate cultures with rhWnt5a reduced ABCG2 mRNA levels compared to untreated controls but had no effect on ABCB1. As ABCG2 expression in primary SCC is much lower than ABCB1 (Fig. 2b), treatment of lung aggregate cultures with rhWnt5a induced changes in drug transporter pattern in vitro that was highly similar to what was detected in primary cancer samples of squamous histology. Based on the above data we concluded that alterations in the Wnt microenvironment differentially affects both $\mathrm{ABCB} 1$ and $\mathrm{ABCG} 2$ expression.

\section{Cisplatin modulates the Wnt microenvironment leading to altered drug transporter activity}

Cisplatin induced multidrug resistance [32] is still a major problem in cancer therapy. While cisplatin up-regulates ABCC1 and ABCC2 (Additional file 3: Figure S3) encoding multidrug resistance-associated protein 1 and 2 (MRP1 and MRP2), there is no explanation why cisplatin would affect $A B C B 1$ or ABCG2 while not being a substrate for either transporters itself $[11,12]$. To investigate, 3D lung aggregates were treated with $29.7 \mu \mathrm{M}$ cisplatin for $72 \mathrm{~h}$, then the canonical Wnt7b and the non-canonical Wnt5a message levels were measured by qRT-PCR (Fig. 3a). Cisplatin down-regulated Wnt5a (Fig. 3a), it also significantly increased the expression of the canonical Wnt7b. Simultaneously, both ABCB1 and ABCG2 mRNA levels (Fig. 3b) increased. The above data are in agreement shown in Fig. 2 where $\mathrm{ABCB} 1$ and $\mathrm{ABCG} 2$ up-regulation was detected in the presence of beta-catenin dependent Wnt pathway activation while inhibition of the same pathway resulted in reduced transporter expression (Fig. 2). To demonstrate that the beta-catenin pathway was activated by cisplatin, control and cisplatin treated 3D aggregate culture sections were stained for beta-catenin and phospho-Ser675-beta-catenin levels [33, 34]. Stabilization and therefore significant increase of beta-catenin protein as well as activated phosphoSer675-beta-catenin was measured in samples following cisplatin treatment (Fig. 3c). Interestingly, Western blot analysis revealed a cisplatin induced cell membrane localization of active beta-catenin (Fig. 3d). To test whether modulation of beta-catenin activity correlates with transporter activity, a functional assay was performed (Fig. 3e). Although inhibition of the canonical Wnt pathway by IWR significantly suppressed $A B C B 1$ but had no effect on ABCG2 activity, activation of the canonical pathway by $10 \mathrm{mM} \mathrm{LiCl}$ slightly but not significantly increased activity of both ABCB1 and ABCG2 transporters compared to untreated controls (Fig. 3e).

\section{Induction of $A B C$ transporter mRNA levels by drugs used in combination therapy}

To test whether paclitaxel, doxorubicin and gemcitabine drugs that are frequently applied in combination therapy
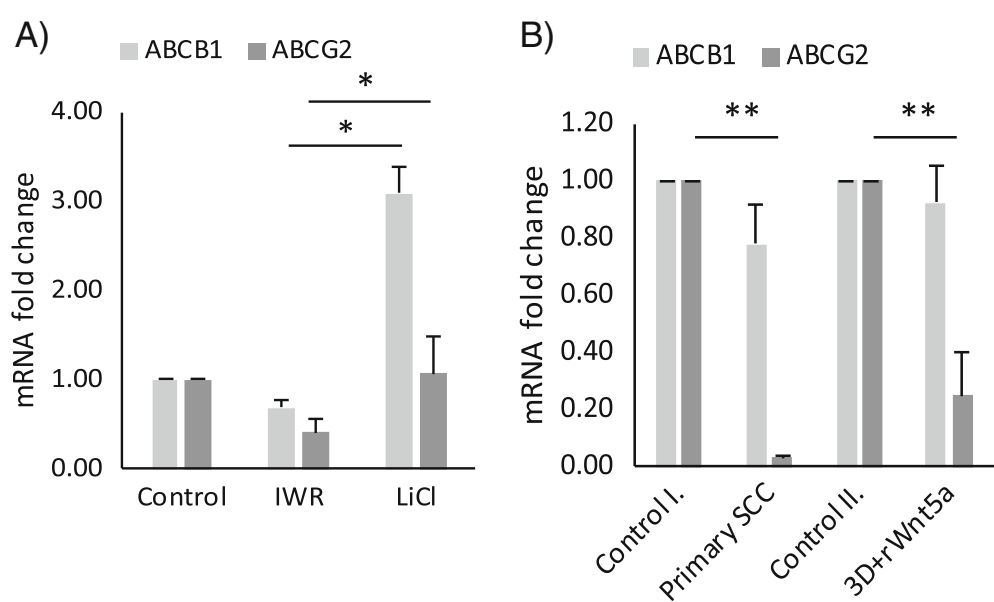

Fig. 2 Wnt dependent differential regulation of drug transporters. Relative mRNA expression of a) $A B C B 1$ and $A B C G 2$ expression in 3D HMVEC-L-NHLF-SAEC aggregates treated with canonical Wht pathway inhibitor, IWR and inducer, LiCl for $3 \mathrm{~h}$. mRNA of treated samples is compared to untreated controls, $n=3$ b) ABCB1 and ABCG2 expression in 3D HMVEC-L-NHLF-SAEC co-culture aggregates following recombinant human Wnt5a treatment shows similar pattern that SCC primary samples. mRNA expression of treated samples is compared to untreated controls, $n=3$, mRNA expression of primary SCC samples is compared to normal lung tissue 

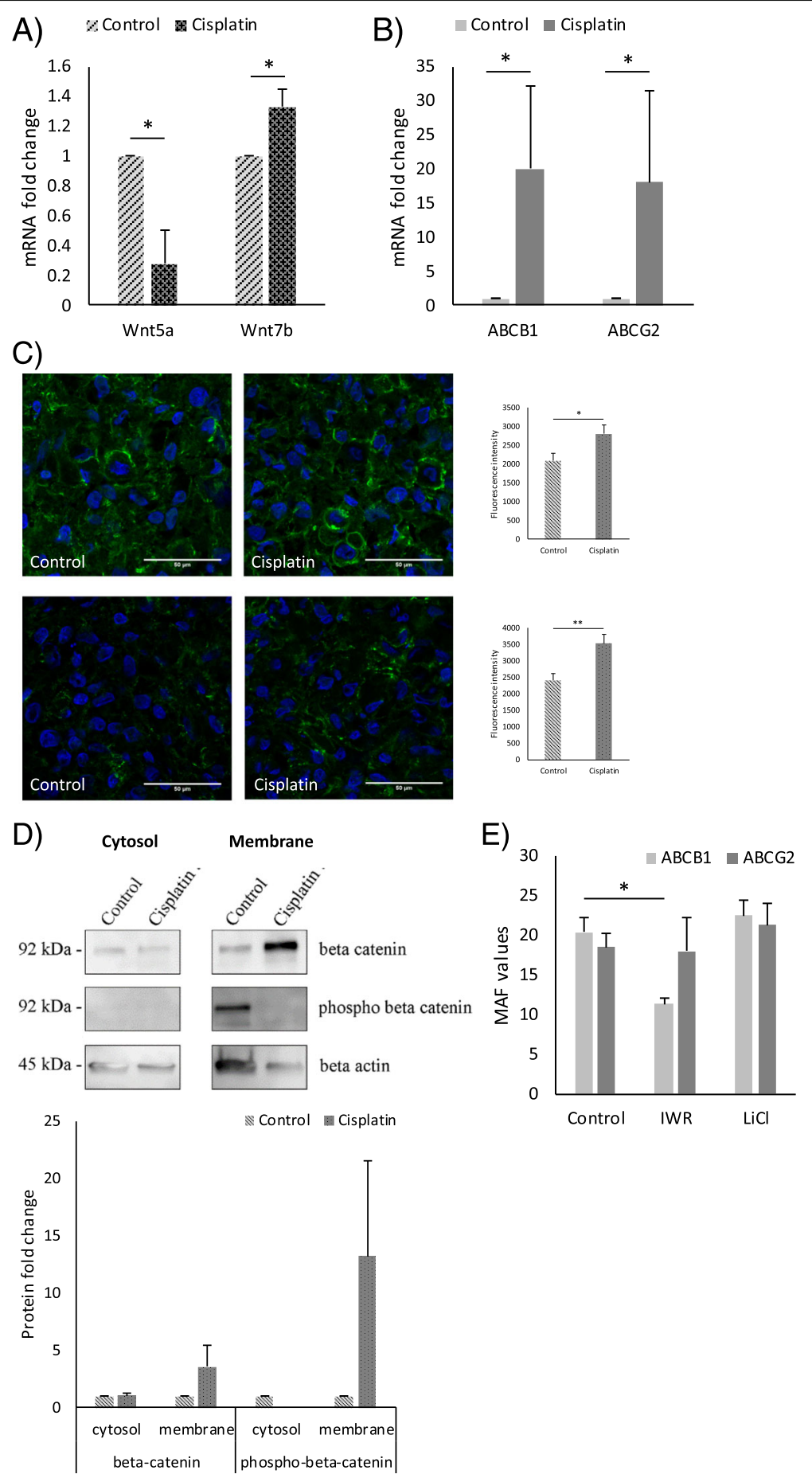

Fig. 3 Effects of cisplatin treatment. Relative mRNA expression of a) Wnt5a and Wnt7b in cisplatin treated 3D HMVEC-L-NHLF-SAEC co-culture aggregates. mRNA expression of treated samples is compared to untreated controls, $n=3 \mathbf{b}$ ) ABCB1 and ABCG2 in cisplatin treated ( $29.7 \mu \mathrm{M}, 3 \mathrm{~h}$ ) 3D HMVEC-L-NHLF-SAEC co-culture aggregates. mRNA expression is normalized to beta-actin, $n=3$ c) Representative images of Ser675 phosphorylated beta-catenin immune-fluorescent staining in control and cisplatin treated 3D HMVEC-L-NHLF-SAEC aggregates. Fluorescence intensity are representations of three different experiments as mean \pm SEM. Scale bar $50 \mu \mathrm{m}$, magnification $63 \times$. d) Western-blot analysis and densitometric quantification of Ser675 phosphorylated beta-catenin and beta-catenin proteins in different cell fractions of control and cisplatin treated A549 lung adenocarcinoma cell cultures, $n=3$ e) functional activity of ABCB1 and ABCG2 drug transporters in 3D co-culture aggregates following canonical Wnt pathway inhibitor, IWR and inducer, LiCl treatment. Data are presented as mean \pm SEM of multidrug resistance activity factor values (MAF), $n=3$. MAF values $\leq 20$ are considered as MDR negative 
can affect $\mathrm{ABC}$ transporter transcription, 3D co-cultures were created using primary human lung fibroblasts (NHLF) and the adenocarcinoma cell line A549 or the squamous cell carcinoma cell line H520. Tissue aggregates then were treated with the above drugs at concentrations of $100 \mathrm{nM}$, respectively, for $48 \mathrm{~h}$. qRT-PCR tests revealed that gemcitabine triggered a significant increase in $\mathrm{ABCB} 1$ and $\mathrm{ABCC} 2$ expression both in adeno and squamous cell carcinoma tissues (Fig. 4a, b) while paclitaxel and doxorubicin differentially initiated drug transporter transcription (Fig. 4a, b). Interestingly, while none of the above drugs increased $\mathrm{ABCC} 1$ transporter mRNA levels in adeno- (A549) or squamous (H520) carcinoma cell line aggregate tissues, $\mathrm{ABCC} 2$ were significantly upregulated by all paclitaxel, doxorubicin and gemcitabine but only in adenocarcinoma cell line (A549) containing aggregate tissues (Fig. 4a, b).

\section{Discussion}

Lung cancers metastasize rapidly and often become inoperable by the time of diagnosis. Cisplatin is the chemotherapeutic drug that is still used in mono- or combination therapies. Resistance to platinum agents, however, invariably develops. The developing multidrug resistance has been characterized as a multifactorial process [35] but the regulatory mechanisms leading to drug resistance are still not completely clear.

Our data revealed that ABCB1 and ABCG2 drug transporters are differentially expressed in NSCLC subtypes AC and SCC where Wnt signaling pathway activity is also different. Using a 3D lung tissue model system it was revealed that treatment of lung tissue with cisplatin up-regulates the multidrug resistance associated protein encoding $\mathrm{ABCC} 1$ and $\mathrm{ABCC} 2$ genes and via modulation of the canonical and non-canonical Wnt pathways increases $\mathrm{ABCB} 1$ and $\mathrm{ABCG} 2$ transporter expression regardless of the fact that cisplatin is not a substrate for the latter two efflux transporters [11, 12]. Inevitably, substrate specificity can also change due to mutations in drug transporter sequences [36] during disease progression. The present report provides an additional layer to the already recognized complexity of drug resistance highlighting the variable tissue microenvironment as a regulatory factor in the process. It has also become clear from the study that the characteristic and rarely mutated Wnt microenvironments in lung cancer subtypes can be mimicked and investigated in vitro. We have shown that specific drug transporter expression is characteristic to NSCLC subtypes but cisplatin can change the characteristically non-canonical (Wnt5a) microenvironment of SCC by activating the beta-catenin dependent route leading to $\mathrm{ABCB} 1$ and $\mathrm{ABCG} 2$ up-regulation. As cisplatin increased the canonical Wnt7b in the study, increase of $\mathrm{ABCB} 1$ and $\mathrm{ABCG} 2$ perhaps is not surprising as previous studies have also demonstrated betacatenin dependent induction of $\mathrm{ABCB} 1[37,38]$ in breast cancer $[39,40]$ and ABCG2 in colon cancer [41]. If betacatenin was knocked down in breast cancer cells, chemosensitivity increased to doxorubicin and etoposide $[39,40]$. In our study treatment with cisplatin triggered beta-catenin localization to the cellular membrane. As beta catenin is a dual function protein, regulating not just gene transcription in the canonical Wnt pathway but the coordination of cell-cell adhesion, such observation might bear additional importance. For efflux transporters to work efficiently, they need to form a functionally active complex [42-44]. If membrane structures e.g. betacatenin-E-cadherin can stabilize lipid rafts [45] to facilitate the assembly of active drug transporter complexes, then cisplatin can increase drug efflux and lower intracellular anti-cancer drug levels in such a way that gene transcription is not even involved in the process.
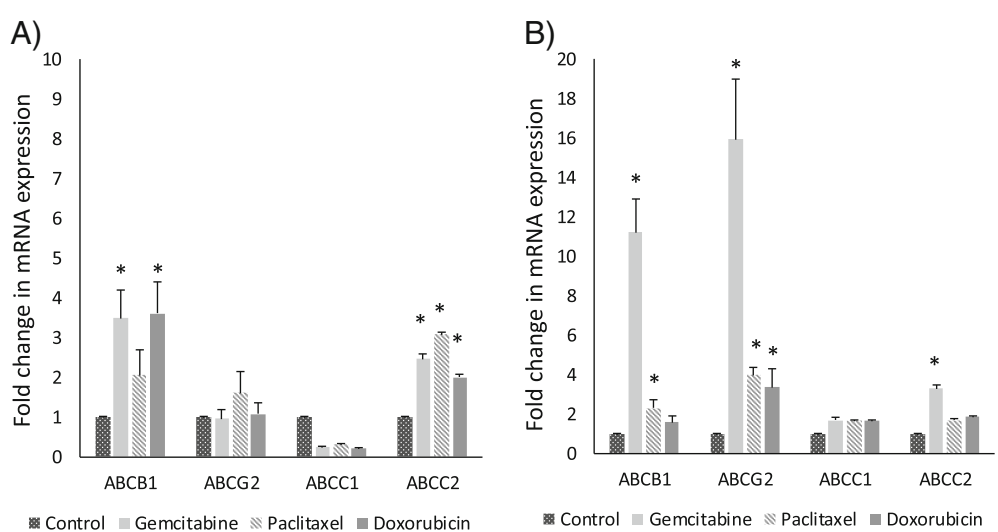

Fig. 4 Effects of paclitaxel, doxorubicin and gemcitabine treatment. Relative mRNA expression of ABCB1, ABCG2, ABCC1 and ABCC2 were studied following treatment of a) 3D co-culture aggregates of adenocarcinoma cell line A549 and NHLF; and b) 3D co-culture aggregates of squamous cell carcinoma cell line H520 and NHLF; with 100 nM paclitaxel, 100 nM doxorubicin, 100 nM gemcitabine for 48 h. mRNA expression was normalized to beta-actin. Data are presented as mean $\pm \mathrm{SEM}, n=3$ 
Additionally, cell membrane localization of beta-catenin is normally associated with E-cadherin binding and a more differentiated epithelial phenotype. Interestingly, ABCG2 can bind to the E-box promoter region of CDH1 (E-cadherin) regulating E-cadherin expression [46]. Low levels of ABCG2 that was detected in resections of primary tumors therefore can be considered as part of the dedifferentiation process leading to low E-cadherin levels and loosened tight junction interactions facilitating cellular migration that is necessary for tumor progression.

Despite extensive studies, the precise biochemical mechanism of cisplatin induced modification of Wnt pathway activity that leads to altered $\mathrm{ABC}$ transporter expression and function is still not fully understood. Connection to epigenetic modification and Wnt pathway activation has been demonstrated in the literature not just for cisplatin [47-49] but for other drugs including paclitaxel, doxorubicin and gemcitabine [50,51]. Further studies, however, needed to reveal the step-by-step biochemical mechanism and to identify molecular targets for intervention. This is particularly important as the clinical consequences are far reaching. Erlotinib and irinotecan are ABCB1 substrates while topotecan, irinotecan and tyrosine kinase inhibitors gefitinib and erlotinib are reported substrates of ABCG2 [52]. ABCG2 can also transport for example doxorubicin [53] which is used to treat brain metastasis of AC-NSCLCs [54].

\section{Conclusion}

Drug transporters are actively involved in a complex regulatory process of drug sensitivity and resistance that is intertwined with epigenetic regulation of Wnt signaling. The present study using resected tissues of primary NSCLC subtypes and an in vitro tissue aggregate model of the lung has provided the following information: a) $\mathrm{ABCB} 1$ and $\mathrm{ABCG} 2$ drug transporters are expressed differentially in AC and SCC tissues, b) drug transporter transcription is affected differentially by cisplatin, paclitaxel, doxorubicin and gemcitabine, and c) and apart from cisplatin, none of the studied drugs increased $A B C C 1$ message levels indicating that in vitro determination of recommended drug administration sequences can be determined to aid more favorable clinical outcome.

\section{Additional files}

Additional file 1: Figure S1. $A B C G 2$ and Wnt7b immunohistochemistry images of primary adeno (AC) and squamous cell carcinoma (SCC) tissues. Representative images of $A B C G 2(B)$ and Wnt7b (B) immunochemistry of primary AC and SCC tissues ( $n=5$, each). Scale bar is $100 \mu \mathrm{m}$ at $20 \times$ magnification and $50 \mu \mathrm{m}$ at 40× magnification images. (DOCX $26321 \mathrm{~kb}$ )

Additional file 2: Figure S2. Establishing a 3D lung tissue aggregate co-culture to model drug transporter expression and activity. Relative mRNA expression of $A B C B 1$ and $A B C G 2$ drug transporters in $A) 2 D$ monocultures, 3D co-culture aggregates (NS: NHLF-SAEC, HNS:
HMVEC-L-NHLF-SAEC), B) in 3D co-culture aggregate (HNS: HMVEC-LNHLF-SAEC) and normal, healthy lung tissue. mRNA expression is relative to beta-actin. In 2D cultures drug transporter expressions are much lower than in the controls. These expression levels increase in 3D culture conditions and all three cell types are needed to become similar to normal lung tissue expression levels. Data are presented as mean \pm SEM, $n=3$ C) representative image of $A B C G 2$ protein expression in $3 D$ co-culture aggregate (HNS: HMVEC-L-NHLF-SAEC), scale bar $50 \mu \mathrm{m}$, magnification; D) functional activity of $A B C B 1$ and $A B C G 2$ drug transporters in $3 D$ HMVEC-LNHLF-SAEC co-culture aggregates. Data are presented as mean \pm SEM of multidrug resistance activity factor values (MAF), $n=3$. MAF values $\geq 20$ are considered as active transporter function. (DOCX $655 \mathrm{~kb}$ )

Additional file 3: Figure S3. Effects of cisplatin in $3 D$ lung tissue tumor cell line aggregates. Relative mRNA expression of $A B C C 1$ and $A B C C 2$ drug transporters of cisplatin treatment of $3 \mathrm{D}$ co-culture aggregates of adenocarcinoma cell line A549-NHLF (A) and (B); 3D co-culture aggregates of squamous cell line H520-NHLF (C) and (D). Data are presented as mean \pm SEM, $n=3$. (DOCX $55 \mathrm{~kb})$

\section{Abbreviations}

ABC transporter: ATP Binding Cassette Family of transporters; ABCB1: ATP Binding Cassette Subfamily B (MDR/TAP) Member 1; ABCG2: ATP Binding Cassette Subfamily G (BCRP) Member 2; AC: adenocarcinoma; ALK: anaplastic lymphoma kinase; AP1: activator protein 1; ATP7A: ATPase copper transporting polypeptide alpha; ATP7B: ATPase copper transporting polypeptide beta; $\mathrm{BSA}$ : bovine serum albumin; $\mathrm{CDH1}$ : cadherin 1; CTR1 = SLC31A1: Solute Carrier Family 31 Member 1; DMEM: Dulbecco's modified eagle medium; EGFR: epidermal growth factor receptor; EGM-2: endothelial cell growth medium; EML4: echinoderm microtubuleassociated protein-like 4; FGM-2: fibroblast growth medium; GSK3ß: Glycogen Synthase Kinase 3 Beta; HMVEC-L: human microvascular endothelial cellslung; IWR: inhibitor od Wnt response; JNK = MAPK8: mitogen-activated protein kinase 8; KRAS: Kirsten Rat Sarcoma Viral Oncogene Homolog; LC: lung cancer; LEF: lymphoid enhancer binding factor; LiCl: Lithium Chloride; MAF: multidrug resistance activity factor; MDR: multidrug resistance; NHLF: normal human lung fibroblasts; NSCLC: non-small cell lung cancer; PBS: phosphate buffered saline; PCP: planar cell polarity;

PFA: paraformaldehyde; PI3KCA: Phosphatidylinositol-4,5-Bisphosphate 3-Kinase, Catalytic Subunit Alpha; PKA: protein kinase A; PKC: protein kinase C; P-ß-catenin: phospho beta catenin; SAEC: small airway epithelial cells; SAGM: small airway epithelial cell growth medium; SCC: squamosus cell carcinoma; SCLC: small cell lung cancer; TCF: transcription factor; WHO: World Health Organization; Wnt: Wingless-Type MMTV Integration Site Family; $\beta$-catenin: beta catenin

\section{Acknowledgements}

The authors are indebted to Prof Mary Keen, Department of Pharmacy and Therapeutics, School of Clinical and Experimental Medicine, College of Medical and Dental Sciences, University of Birmingham for discussions and language editing.

\section{Funding}

JEP was supported by the European Union and the State of Hungary, co-financed by the European Social Fund in the framework of TAMOP4.2.4.A/2-11/1-2012-0001 'National Excellence Program'.

\section{Availability of data or data sets}

All data generated or analysed during this study are included in this published article [and its supplementary information files].

\section{Authors' contributions}

MV, JR: performed the experiments, MV, EK, DF: isolated RNA from lung tissues, MM: performed flow cytometry, JR: confocal microscopic analysis, LJ, GM: preparing all the statistics and English corrections. VS, TL, GS: provided the lung tissue and performed staining and analysis of primary human lung tissues, diagnosis, BD: Western blotting and scanning, JEP designed the studies, JR, MV, IK and JEP have written the manuscript. All authors read and approved the final manuscript. 


\section{Competing interests}

The author(s) declare(s) that they have no competing interests. Except for the aggregate tissue model where MV, JR, DB, MM, DF, EK and JEP are declare competing interests.

\section{Consent for publication}

Not applicable.

\section{Ethics approval and consent to participate}

Lung tissue samples were collected at the Department of Surgery coordinated by the Department of Pathology, University of Pecs, Hungary. The project was approved by the Ethical Committee of the University of Pecs (ETT-TUKEB 366/ 2015). Patients had given written consent to provide samples for research purposes. All collected samples were treated anonymously.

\section{Publisher's Note}

Springer Nature remains neutral with regard to jurisdictional claims in published maps and institutional affiliations.

\section{Author details}

${ }^{1}$ Department of Pharmaceutical Biotechnology, School of Pharmacy, University of Pecs, Pecs, Hungary. ${ }^{2}$ Department of Pathology, School of Medicine, University of Pecs, Pecs, Hungary. ${ }^{3}$ Department of Microbiology and Immunology, School of Medicine, University of Pecs, Pecs, Hungary. ${ }^{4}$ Szentagothai Research Centre, University of Pecs, Pecs, Hungary. ${ }^{5}$ Humeltis Ltd, Pecs, Hungary. ${ }^{6}$ Scientific Unit, Osijek University Hospital, Huttlerova 4, Osijek HR31000, Croatia. ${ }^{7}$ Department of Pathophysiology, Faculty of Medicine, University of Osijek, Cara Hadrijana 10, Osijek HR31300, Croatia.

\section{Received: 23 September 2016 Accepted: 14 March 2017}

\section{Published online: 24 March 2017}

\section{References}

1. Wangari-Talbot J, Hopper-Borge E. Drug Resistance Mechanisms in NonSmall Cell Lung Carcinoma. J. Can. Res. Updates. 2013 [cited 19 Sep 2016];2: 265-82. Available from: http://www.ncbi.nlm.nih.gov/pubmed/24634705

2. Siegel R, Naishadham D, Jemal A. Cancer statistics, 2012. CA. Cancer J. Clin [cited 19 Sep 2016];62:10-29. Available from: http://www.ncbi.nlm.nih.gov/ pubmed/22237781

3. Stahel R, Thatcher N, Früh M, Le Péchoux C, Postmus PE, Sorensen JB, et al. 1st ESMO Consensus Conference in lung cancer; Lugano 2010: small-cell lung cancer. Ann. Oncol. Oxford University Press; 2011 [cited 19 Sep 2016];22:1973-80. Available from: http://www.ncbi.nlm.nih.gov/ pubmed/21727198

4. Vansteenkiste J, Crinò L, Dooms C, Douillard JY, Faivre-Finn C, Lim E, et al. 2nd ESMO Consensus Conference on Lung Cancer: early-stage non-smallcell lung cancer consensus on diagnosis, treatment and follow-up. Ann. Oncol.2014 [cited 19 Sep 2016];25:1462-74. Available from: http://www.ncbi. nlm.nih.gov/pubmed/24562446

5. Korpanty GJ, Graham DM, Vincent MD, Leighl NB. Biomarkers That Currently Affect Clinical Practice in Lung Cancer: EGFR, ALK, MET, ROS-1, and KRAS Front. Oncol. 2014 [cited 19 Sep 2016];4:204. Available from: http://www. ncbi.nlm.nih.gov/pubmed/25157335

6. Johnson JL, Pillai S, Chellappan SP, Johnson JL, Pillai S, Chellappan SP. Genetic and Biochemical Alterations in Non-Small Cell Lung Cancer. Biochem. Res. Int. Hindawi Publishing Corporation; 2012 [cited 19 Sep 2016];2012:1-18. Available from: http://www.hindawi.com/journals/bri/ 2012/940405/

7. Molina JR, Yang P, Cassivi SD, Schild SE, Adjei AA. Non-small cell lung cancer: epidemiology, risk factors, treatment, and survivorship. Mayo Clin. Proc. NIH Public Access; 2008 [cited 19 Sep 2016];83:584-94. Available from: http://www.ncbi.nlm.nih.gov/pubmed/18452692

8. Sundar R, Cho B-C, Brahmer JR, Soo RA. Nivolumab in NSCLC: latest evidence and clinical potential. Ther. Adv. Med. Oncol. SAGE Publications; 2015 [cited 20 Sep 2016];7:85-96. Available from: http://www.ncbi.nlm.nih. gov/pubmed/25755681

9. Ciarimboli G. Membrane transporters as mediators of cisplatin side-effects. Anticancer Res. 2014 [cited 19 Sep 2016];34:547-50. Available from: http:// www.ncbi.n/m.nih.gov/pubmed/24403515

10. Kuo MT, Chen HHW, Song I-S, Savaraj N, Ishikawa T. The roles of copper transporters in cisplatin resistance. Cancer Metastasis Rev. 2007 [cited 19
Sep 2016];26:71-83. Available from: http://www.ncbi.n/m.nih.gov/pubmed/ 17318448

11. Yin J-Y, Huang Q, Yang $Y$, Zhang J-T, Zhong $M-Z$, Zhou $H-H$, et al. Characterization and analyses of multidrug resistance-associated protein 1 (MRP1/ABCC1) polymorphisms in Chinese population. Pharmacogenet. Genomics. NIH Public Access; 2009 [cited 8 Feb 2017];19:206-16. Available from: http://www.ncbi.nlm.nih.gov/ pubmed/19214144

12. Wang $X-K$, To KKW, Huang L-Y, Xu J-H, Yang $K$, Wang $F$, et al. Afatinib circumvents multidrug resistance via dually inhibiting ATP binding cassette subfamily G member 2 in vitro and in vivo. Oncotarget. 2014 [cited 2016 Sep 19];5:11971-85. Available from:http://www.ncbi.nlm.nih. gov/pubmed/25436978

13. Yoh K, Ishii G, Yokose T, Minegishi Y, Tsuta K, Goto K, et al. Breast cancer resistance protein impacts clinical outcome in platinum-based chemotherapy for advanced non-small cell lung cancer. Clin. Cancer Res. 2004 [cited 19 Sep 2016];10:1691-7. Available from: http://www.ncbi.nlm. nih.gov/pubmed/15014021

14. Leonard GD, Fojo T, Bates SE. The role of $A B C$ transporters in clinica practice. Oncologist. 2003 [cited 19 Sep 2016];8:411-24. Available from: http://www.ncbi.nlm.nih.gov/pubmed/14530494

15. Merk J, Rolff J, Dorn C, Leschber G, Fichtner I. Chemoresistance in nonsmall-cell lung cancer: can multidrug resistance markers predict the response of xenograft lung cancer models to chemotherapy? Eur. J. Cardiothorac. Surg. 2011 [cited 19 Sep 2016];40:e29-33. Available from: http://www.ncbi.nlm.nih.gov/pubmed/21420313

16. Chiou JF, Liang JA, Hsu WH, Wang JJ, Ho ST, Kao A. Comparing the relationship of Taxol-based chemotherapy response with P-glycoprotein and lung resistance-related protein expression in non-small cell lung cancer. Lung. 2003 [cited 19 Sep 2016];181:267-73. Available from: http://www.ncbi. nlm.nih.gov/pubmed/14705770

17. Stacy $A E$, Jansson PJ, Richardson DR. Molecular pharmacology of ABCG2 and its role in chemoresistance. Mol. Pharmacol. 2013 [cited 19 Sep 2016];84:655-69. Available from: http://www.ncbi.n/m.nih.gov/pubmed/ 24021215

18. Abdullah LN, Chow EK-H. Mechanisms of chemoresistance in cancer stem cells. Clin. Transl. Med. 2013 [cited 19 Sep 2016];2:3. Available from: http:// www.ncbi.n/m.nih.gov/pubmed/23369605

19. Pongracz JE, Stockley RA. Wnt signalling in lung development and diseases. Respir. Res. 2006 [cited 9 Sep 2015];7:15. Available from: http://www. pubmedcentral.nih.gov/articlerender.fcgi?artid=1397816\&tool= pmcentrez\&rendertype=abstract

20. Corrêa S, Binato R, Du Rocher B, Castelo-Branco MTL, Pizzatti L, Abdelhay E. Wnt/B-catenin pathway regulates $A B C B 1$ transcription in chronic myeloid leukemia. BMC Cancer. 2012 [cited 19 Sep 2016];12:303. Available from: http://www.ncbi.nlm.nih.gov/pubmed/22823957

21. Lim JC, Kania KD, Wijesuriya H, Chawla S, Sethi JK, Pulaski L, et al. Activation of beta-catenin signalling by GSK-3 inhibition increases p-glycoprotein expression in brain endothelial cells. J. Neurochem. 2008 [cited 19 Sep 2016];106:1855-65. Available from: http://www.ncbi.nlm.nih.gov/pubmed/ 18624906

22. Flahaut M, Meier R, Coulon A, Nardou KA, Niggli FK, Martinet D, et al. The Wnt receptor FZD1 mediates chemoresistance in neuroblastoma through activation of the Wnt/beta-catenin pathway. Oncogene. 2009 [cited 19 Sep 2016];28:2245-56. Available from: http://www.ncbi.nlm.nih. gov/pubmed/19421142

23. Bartis D, Csongei V, Weich A, Kiss E, Barko S, Kovacs T, et al. Downregulation of canonical and up-regulation of non-canonical Wnt signalling in the carcinogenic process of squamous cell lung carcinoma. PLoS One. 2013 [cited 20 Jul 2015];8:e57393. Available from: http://www. pubmedcentral.nih.gov/articlerender.fcgi?artid=3591434\&tool= pmcentrez\&rendertype=abstract

24. Lee EHL, Chari R, Lam A, Ng RT, Yee J, English J, et al. Disruption of the non-canonical WNT pathway in lung squamous cell carcinoma. Clin. Med. Oncol. Libertas Academica; 2008 [cited 19 Sep 2016];2008:169-79. Available from: http://www.ncbi.nlm.nih.gov/pubmed/20401333

25. Barr MP, Gray SG, Hoffmann AC, Hilger RA, Thomale J, O'Flaherty JD, et al. Generation and Characterisation of Cisplatin-Resistant Non-Small Cell Lung Cancer Cell Lines Displaying a Stem-Like Signature. Yang P-C, editor. PLoS One. Public Library of Science; 2013 [cited 19 Sep 2016];8:e54193. Available from: http://dx.plos.org/10.1371/journal.pone.0054193 
26. Home page - Cancerrxgene - Genomics of Drug Sensitivity in Cancer. [cited 8 Feb 2017]. Available from: http://www.cancerrxgene.org/

27. Geraghty RJ, Capes-Davis A, Davis JM, Downward J, Freshney RI, Knezevic I, et al. Guidelines for the use of cell lines in biomedical research. Br. J. Cancer. 2014 [cited 19 Sep 2016];111:1021-46. Available from: http://www.ncbi.nlm. nih.gov/pubmed/25117809

28. Kovacs T, Csongei V, Feller D, Ernszt D, Smuk G, Sarosi V, et al. Alteration in the Wnt microenvironment directly regulates molecular events leading to pulmonary senescence. Aging Cell. 2014 [cited 20 Jul 2015];13:838-49. Available from: http://www.pubmedcentral.nih.gov/articlerender.fcgi?artid= 4331750\&tool=pmcentrez\&rendertype =abstract

29. Haq S, Michael A, Andreucci M, Bhattacharya K, Dotto P, Walters B, et al. Stabilization of beta-catenin by a Wnt-independent mechanism regulates cardiomyocyte growth. Proc. Natl. Acad. Sci. U. S. A. 2003 [cited 13 Nov 2015];100:4610-5. Available from: http://www.pnas.org/ content/100/8/4610.full

30. Schindelin J, Arganda-Carreras I, Frise E, Kaynig V, Longair M, Pietzsch T, et al. Fiji: an open-source platform for biological-image analysis. Nat. Methods. Nature Research; 2012 [cited 26 Jul 2016];9:676-82. Available from: http://www.nature.com/doifinder/10.1038/nmeth.2019

31. Haq S, Michael A, Andreucci M, Bhattacharya K, Dotto P, Walters B, et al. Stabilization of beta-catenin by a Wnt-independent mechanism regulates cardiomyocyte growth. Proc. Natl. Acad. Sci. U. S. A. National Academy of Sciences; 2003 [cited 7 Sep 2016];100:4610-5. Available from: http://www. ncbi.nlm.nih.gov/pubmed/12668767

32. Florea A-M, Büsselberg D. Cisplatin as an anti-tumor drug: cellular mechanisms of activity, drug resistance and induced side effects. Cancers (Basel). Multidisciplinary Digital Publishing Institute (MDPI); 2011 [cited 19 Sep 2016];3:1351-71. Available from: http://www.ncbi.nlm.nih. gov/pubmed/24212665

33. Taurin S, Sandbo N, Qin Y, Browning D, Dulin NO. Phosphorylation of betacatenin by cyclic AMP-dependent protein kinase. J. Biol. Chem. 2006 [cited 19 Sep 2016];281:9971-6. Available from: http://www.ncbi.nlm.nih.gov/ pubmed/16476742

34. Hino S, Tanji C, Nakayama Kl, Kikuchi A. Phosphorylation of beta-catenin by cyclic AMP-dependent protein kinase stabilizes beta-catenin through inhibition of its ubiquitination. Mol. Cell. Biol. 2005 [cited 19 Sep 2016];25: 9063-72. Available from: http://www.ncbi.nlm.nih.gov/pubmed/16199882

35. Gillet J-P, Gottesman MM. Mechanisms of multidrug resistance in cancer. Methods Mol. Biol. 2010 [cited 19 Sep 2016];596:47-76. Available from: http://www.ncbi.nlm.nih.gov/pubmed/19949920

36. Robey RW, Honjo Y, Morisaki K, Nadjem TA, Runge S, Risbood M, et al. Mutations at amino-acid 482 in the ABCG2 gene affect substrate and antagonist specificity. Br. J. Cancer. 2003 [cited 19 Sep 2016];89:1971-8. Available from: http://www.ncbi.nlm.nih.gov/pubmed/14612912

37. Yamada T, Takaoka AS, Naishiro Y, Hayashi R, Maruyama K, Maesawa C, et al. Transactivation of the multidrug resistance 1 gene by T-cell factor 4/betacatenin complex in early colorectal carcinogenesis. Cancer Res. 2000 [cited 19 Sep 2016];60:4761-6. Available from: http://www.ncbi.nlm.nih.gov/ pubmed/10987283

38. Yamada H, Furuuchi K, Aoyama T, Kataoka A, Hamada J, Tada M, et al. Reconstructed beta-catenin/TCF4 signaling in yeast applicable to functional evaluation of APC mutations. Am. J. Pathol. 2003 [cited 19 Sep 2016];163: 2201-9. Available from: http://www.ncbi.nlm.nih.gov/pubmed/14633595

39. Bourguignon LYW, Xia W, Wong G. Hyaluronan-mediated CD44 interaction with p300 and SIRT1 regulates beta-catenin signaling and NFkappaB-specific transcription activity leading to MDR1 and $\mathrm{BCl}-\mathrm{xL}$ gene expression and chemoresistance in breast tumor cells. J. Biol. Chem. 2009 [cited 19 Sep 2016];284:2657-71. Available from: http://www.ncbi.nlm.nih.gov/pubmed/ 19047049

40. Liu Y-Y, Gupta V, Patwardhan GA, Bhinge K, Zhao Y, Bao J, et al. Glucosylceramide synthase upregulates MDR1 expression in the regulation of cancer drug resistance through cSrc and beta-catenin signaling. Mol. Cancer. 2010 [cited 19 Sep 2016];9:145. Available from: http://www.ncbi.nlm. nih.gov/pubmed/20540746

41. Chikazawa N, Tanaka H, Tasaka T, Nakamura M, Tanaka M, Onishi H, et al. Inhibition of Wnt signaling pathway decreases chemotherapy-resistant sidepopulation colon cancer cells. Anticancer Res. 2010 [cited 19 Sep 2016];30: 2041-8. Available from: http://www.ncbi.nlm.nih.gov/pubmed/20651349

42. Dezi M, Fribourg P-F, Di Cicco A, Arnaud O, Marco S, Falson P, et al. The multidrug resistance half-transporter $A B C G 2$ is purified as a tetramer upon selective extraction from membranes. Biochim. Biophys. Acta. 2010 [cited 19 Sep 2016];1798:2094-101. Available from: http://www.ncbi.nlm.nih.gov/ pubmed/20691149

43. Mo W, Zhang J-T. Human ABCG2: structure, function, and its role in multidrug resistance. Int. J. Biochem. Mol. Biol. 2012 [cited 19 Sep 2016];3:1-27. Available from: http://www.ncbi.nlm.nih.gov/pubmed/22509477

44. Zgurskaya HI. Multicomponent drug efflux complexes: architecture and mechanism of assembly. Future Microbiol. 2009 [cited 19 Sep 2016];4:919-32. Available from: http://www.ncbi.nlm.nih.gov/pubmed/19722844

45. Yun U-J, Lee J-H, Koo KH, Ye S-K, Kim S-Y, Lee C-H, et al. Lipid raft modulation by Rp1 reverses multidrug resistance via inactivating MDR-1 and Src inhibition. Biochem. Pharmacol. 2013 [cited 19 Sep 2016];85:1441-53. Available from: http://www.ncbi.nlm.nih.gov/pubmed/23473805

46. Liang S-C, Yang C-Y, Tseng J-Y, Wang H-L, Tung C-Y, Liu H-W, et al. ABCG2 localizes to the nucleus and modulates $\mathrm{CDH} 1$ expression in lung cancer cells. Neoplasia. 2015 [cited 19 Sep 2016];17:265-78. Available from: http:// www.ncbi.nlm.nih.gov/pubmed/25810011

47. O'Byrne KJ, Barr MP, Gray SG. The Role of Epigenetics in Resistance to Cisplatin Chemotherapy in Lung Cancer. Cancers (Basel). 2011 [cited 8 Feb 2017];3:1426-53. Available from: http://www.ncbi.nlm.nih.gov/ pubmed/24212667

48. Su H-Y, Lai H-C, Lin Y-W, Liu C-Y, Chen C-K, Chou Y-C, et al. Epigenetic silencing of SFRP5 is related to malignant phenotype and chemoresistance of ovarian cancer through Wnt signaling pathway. Int. J. Cancer. 2010 [cited 8 Feb 2017];127:555-67. Available from: http://www.ncbi.nlm.nih.gov/ pubmed/19957335

49. Okamoto J, Hirata T, Chen Z, Zhou H-M, Mikami I, Li H, et al. EMX2 is epigenetically silenced and suppresses growth in human lung cancer. Oncogene. NIH Public Access; 2010 [cited 8 Feb 2017];29:5969-75. Available from: http://www.ncbi.nlm.nih.gov/pubmed/20697358

50. Sanchez AM, Giorgione V, Vigano P, Papaleo E, Candiani M, Mangili G, et al. Treatment With Anticancer Agents Induces Dysregulation of Specific Wnt Signaling Pathways in Human Ovarian Luteinized Granulosa Cells In Vitro. Toxicol. Sci. 2013 [cited 8 Feb 2017];136:183-92. Available from: http://www ncbi.nlm.nih.gov/pubmed/23956100

51. Nagano H, Tomimaru $Y$, Eguchi $H$, Hama N, Wada $H$, Kawamoto $K$, et al. MicroRNA-29a induces resistance to gemcitabine through the Wnt/ $\beta$ catenin signaling pathway in pancreatic cancer cells. Int. J. Oncol. 2013 [cited 8 Feb 2017];43:1066-72. Available from: http://www.ncbi.nlm.nih.gov/ pubmed/23900458

52. Yang Y, Li H, Hou S, Hu B, Liu J, Wang J. The noncoding RNA expression profile and the effect of InCRNA AK126698 on cisplatin resistance in nonsmall-cell lung cancer cell. PLoS One. 2013 [cited 19 Sep 2016];8:e65309. Available from: http://www.ncbi.n/m.nih.gov/pubmed/23741487

53. Singhal S, Singhal J, Nair M, Lacko A, Awasthi Y, Awasthi S. Doxorubicin transport by RALBP1 and ABCG2 in lung and breast cancer. Int. J. Oncol. 2007 [cited 20 Sep 2016]; Available from: http://www.spandidospublications.com/10.3892/ijo.30.3.717

54. Zhu W, Zhou L, Qian J-Q, Qiu T-Z, Shu Y-Q, Liu P. Temozolomide for treatment of brain metastases: A review of 21 clinical trials. World J. Clin. Oncol. Baishideng Publishing Group Inc; 2014 [cited 20 Sep 2016];5:19-27. Available from: http://www.ncbi.n/m.nih.gov/pubmed/24527399

\section{Submit your next manuscript to BioMed Central and we will help you at every step:}

- We accept pre-submission inquiries

- Our selector tool helps you to find the most relevant journal

- We provide round the clock customer support

- Convenient online submission

- Thorough peer review

- Inclusion in PubMed and all major indexing services

- Maximum visibility for your research

Submit your manuscript at www.biomedcentral.com/submit 